\title{
PERAN LAPAS DAN LAPASUSTIK PADA RESIDIVIS NARKOBA PENGGUNA
}

\author{
Sri Aryanti Kristianingsih, \\ Suryanto, Yusti Probowati Rahayu \\ Universitas Airlangga |Jl. Airlangga 4-6 Surabaya | sri.kristianingsih@uksw.edu \\ Universitas Airlangga | Jl. Airlangga 4-6 Surabaya | suryanto02@yahoo.com \\ Universitas Surabaya | Jl. Tenggilis Mejoyo, Kali Rungkut Surabaya \\ |yustiprobowati@gmail.com
}

\begin{abstract}
Prisons and Drug Abuse Correctional Centre (DACC) play a significant role in recidivism. This study aims to understand the role of prisons and DACC in drug user recidivists, the implementation of Law no. 12 of 1995 concerning correctional facilities, and the law. No. 35 of 2009 concerning narcotics to find out how the process of guidance in prisons and DACC for drug user recidivists, and to find out the effectiveness of coaching in both prisons. This qualitative research uses a case study approach. The data collection method used interviews with 8 subjects and observations on the subject and prison conditions. The data analysis method combines the analysis stages of Morse and Miles and Huberman. Purposive sampling technique was used, with the criteria of the research subjects: drug user recidivists; have experienced convictions in prisons and DACC; of legal age; case of article 127 of Law no. 35 of 2009 concerning Narcotics or article 36 of Law No. 5 of 1997 concerning Psychotropics and in conjunction with other articles; $\mathrm{BI}$ and Blla classification; the level of drug use is not addiction. The results showed that these two laws have not been fully implemented in prisons and DACC. This is evidenced by the different treatment of prison officers, while the treatment of DACC officers is the same and more humane to DACC so that it has an impact on recidivism. In both, there is personality development and independence but still emphasizes religious development. Medical and social rehabilitation is perceived as ineffective. The two correctional institutions do not raise self-contempt but do raise a cognitive bias. Prison and DACC are different environments that play an important role in becoming drug user recidivists, but DACC is an environment that is more
\end{abstract}


conducive to achieve the correctional goals for drug user recidivists.Keywords: Role, prisons, DACC, drug user recidivists

\begin{abstract}
Abstrak: Lapas maupun lapasustik berperan pada residivisme. Penelitian ini bertujuan untuk memahami peran lapas dan lapasustik pada residivis narkoba pengguna, implementasi UU No. 12 Tahun 1995 tentang pemasyarakatan dan UU. No. 35 Tahun 2009 tentang narkotika, khususnya untuk mengetahui bagaimana proses pembinaan di lapas maupun lapasustik pada residivis narkoba pengguna, dan mengetahui efektivitas pembinaan pada kedua tempat tersebut. Penelitian ini adalah penelitian kualitatif dengan pendekatan studi kasus. Metode pengambilan data menggunakan wawancara pada 8 subjek serta observasi pada subjek dan kondisi lapas. Metode analisis data mengkombinasi tahapan analisis Morse serta Miles dan Huberman. Teknik purposive sampling digunakan, dengan kriteria subjek penelitian: residivis narkoba pengguna; pernah mengalami pemidanaan di lapas maupun lapasustik; berusia dewasa secara hukum; kasus pasal I 27 UU No. 35 Tahun 2009 tentang Narkotika atau pasal 36 UU No 5 Tahun 1997 tentang Psikotropika maupun juncto pasal lainnya; klasifikasi BI dan Blla; tingkat penggunaan narkoba belum adiksi. Hasil penelitian menunjukkan bahwa kedua undang-undang tersebut belum terimplementasi sepenuhnya pada lapas maupun lapasustik. Dibuktikan dari perlakuan petugas lapas yang berbeda, sementara perlakuan petugas lapasustik sama dan lebih humanis, sehingga berdampak pada residivisme. Pada keduanya terdapat pembinaan kepribadian maupun kemandirian, namun masih menekankan pembinaan keagamaan. Rehabilitasi medis dan sosial dipersepsikan belum efektif. Kedua lapas tidak memunculkan self contempt, namun memunculkan bias kognitif. Lapas maupun lapasustik menjadi lingkungan yang berperan penting secara berbeda untuk menjadi residivis narkoba pengguna, namun lapasustik merupakan lingkungan yang lebih kondusif dalam mencapai tujuan pemasyarakatan bagi residivis narkoba pengguna.
\end{abstract}

Kata kunci: Peran, lapas, lapasustik, residivis narkoba pengguna

\title{
Pendahuluan
}

Narkoba termasuk dalam jenis kejahatan yang menonjol di Indonesia dan cenderung mengalami peningkatan. Hal ini nampak dari pertambahan populasi tahanan, narapidana, maupun residivis yang semakin meningkat di Lembaga Pemasyarakatan (Lapas). 
Berdasarkan data Kemenhumham ${ }^{1}$ jumlah tahanan dan narapidana (termasuk residivis) di seluruh Indonesia pada 2018 adalah 256.273 orang, dengan peningkatan rata-rata 22.000 orang per tahunnya, serta jumlah penambahan terbanyak adalah kasus narkoba, yaitu 74.037 bandar narkoba dan 41.252 narapidana narkoba. Menurut laporan Kanwil Kemenhumham DKI Jakarta tahun $2019^{2}$ warga binaan pemasyarakatan (WBP) narkotika yang pernah terlibat dalam kasus yang sama sebagai narapidana minimal satu kali (residivis) sekitar 31,3 persen.

Jumlah narapidana di Indonesia mengalami peningkatan, namun data residivis di Indonesia secara pasti masih sulit diketahui jumlahnya, karena penetapan residivis hanya berdasarkan informasi/pengakuan yang bersangkutan pada saat registrasi di Lapas (Berdasarkan wawancara dengan petugas bagian registrasi Lapas Kelas IIA Worogunan Yogyakarta, 13 Juni 2014). Residivis dalam pemahaman umum diartikan sebagai orang yang melakukan pengulangan tindak pidana $^{3}$. Residivisme dalam pemahaman umum dipahami sebagai suatu istilah luas yang mengacu pada perilaku kriminal kambuhan (relapse of criminal behavior), termasuk karena suatu penangkapan kembali (rearrest), penjatuhan pidana kembali (reconviction), dan pemenjaraan kembali (reimprisonment) ${ }^{4}$. Pengertian residivis maupun residivisme dalam penelitian ini mengacu pada $\mathrm{KBBI}^{5}$ maupun dalam Kitab Undang-Undang Hukum Pidana, yaitu residivis adalah orang yang pernah dihukum dan telah mendapatkan putusan pengadilan yang telah mempunyai

\footnotetext{
I Fana Suparman, Napi Narkoba Bikin Lapas dan Rutan di Indonesia Kelebihan Kapasitas, Berita Satu (27 Desember 2018), dalam https://www.beritasatu.com/nasional/529886-napi-narkobabikin-lapas-dan-rutan-di-indonesia-kelebihan-kapasitas

${ }^{2}$ Laporan Kegiatan Pengkajian Hak Manusia di Wilayah Karakteristik Narapidana Kasus Narkotika oleh Bidang Hak Asasi Manusia Divisi Pelayanan Hukum dan HAM Kantor Wilayah Kementrian Hukum dan HAM DKI Jakarta tahun 2019

3 Aruan Sakidjo dan Bambang Poernomo, Hukum Pidana Dasar Aturan Umum Hukum Pidana Kodifikasi (Jakarta: Ghalia Indonesia, 1990), I8I.

${ }^{4}$ Fazel S dan Wolf A, "A Systematic Review of Criminal Recidivism Rates Worldwide: Current Difficulties and Recommendations for Best Practice", PLoS ONE 10(6): e0I30390. doi: 10.137|/journal.pone.0130390, June 18, 2015, I-8

${ }^{5}$ Kamus Besar Bahasa Indonesia, (Edisi ketiga) (Jakarta : Balai Pustaka, 2002)
} 
kekuatan hukum yang tetap, kemudian mengulangi tindak kejahatan yang serupa (dalam konteks penelitian ini adalah kasus narkoba). Pengertian residivisme dalam penelitian ini, yaitu pengulangan suatu tindak pidana yang sama oleh pelaku yang sama, yang mana tindak pidana yang dilakukan sebelumnya telah dijatuhi pidana dan berkekuatan hukum tetap, serta pengulangan terjadi dalam jangka waktu tertentu yang menjadikan orang tersebut kembali menjadi narapidana.

Meningkatnya jumlah narapidana kasus narkotika (termasuk residivis) menyebabkan kelebihan kapasitas di dalam Lapas dan Lapas Khusus Narkotika (Lapasustik). Menurut data Direktorat Jenderal Pemasyarakatan (Ditjen PAS) per tanggal 31 Desember 20186, dari total 22 UPT khusus narkotika di Indonesia, memiliki daya tampung sebanyak 11.659 narapidana. Namun, jumlah narapidana kasus narkotika yang menempatinya mencapai 19.993 narapidana atau mengalami kelebihan kapasitas sebesar $71,4 \%$. Narapidana kasus narkotika termasuk residivis tidak seluruhnya dapat tertampung di dalam lapasustik. Sebagian besar tersebar di berbagai lapas dan rumah tahanan (rutan) di Indonesia.

Idealnya narapidana maupun residivis narkoba di tempatkan di lapasustik, karena lapasustik menurut Sasangka ${ }^{7}$ merupakan lembaga khusus yang diperuntukkan bagi narapidana kasus narkotika, berdiri sendiri dengan pola pembinaan berbeda dengan lapas umum, yaitu menggunakan aspek penanganan dan pendekatan yang meliputi aspek perawatan dan aspek kesehatan narapidana. Hal tersebut sesuai dengan pasal 54 UU No.35 tahun 2009 tentang narkotika, yang menyebutkan bahwa pecandu narkotika dan korban penyalahgunaan narkotika wajib menjalani rehabilitasi medis dan rehabilitasi sosial. Hal ini menunjukkan bahwa UU No. 35 tahun 2009 tentang narkotika menganut double track system pemidanaan, sehingga mereka yang melakukan

\footnotetext{
${ }^{6}$ Laporan Kegiatan Pengkajian Hak Manusia di Wilayah Karakteristik Narapidana Kasus Narkotika oleh Bidang Hak Asasi Manusia Divisi Pelayanan Hukum dan HAM Kantor Wilayah Kementrian Hukum dan HAM DKI Jakarta tahun 2019

${ }^{7}$ Hari Sasangka, Narkotika dan Psikotropika dalam Hukum Pidana (Bandung: Mandar Maju, 2003)
} 
penyalahgunaan narkotika dapat dihukum pidana dan dapat dihukum rehabilitasi atau dihukum pidana dan ditambah hukuman rehabilitasi (Pasal 36 UU No. 8 Tahun 1976 dan Pasal 103 UU No. 35 Tahun 2009).

Sesuai dengan amanat UU narkotika tersebut, bagi para narapidana narkotika, selain melaksanakan pola pembinaan secara umum, lapas maupun lapasustik juga melakukan program rehabilitasi. Program rehabilitasi ini biasanya dilakukan dengan bekerja sama dengan BNN. Program rehabilitasi ini dilakukan dengan menggunakan model Therapeutic Community (TC), yang merupakan suatu program rehabilitasi bagi pecandu narkoba dengan membentuk suatu komunitas positif dalam lingkungan teratur dan terkoordinir dengan kegiatan-kegiatan yang menunjang perubahan secara fisik maupun mental. (Buku Program Rehabilitasi Modalitas Therapeutic Community Lapas Narkotika Kelas IIA Yogyakarta, 1 Oktober 2015).

Selama ini kebijakan legal terkait rehabilitasi penyalahguna narkotika masih belum sepenuhnya terimplementasi dengan baik. Hal ini akibat adanya tarik menarik di antara para pengambil kebijakan di bidang kesehatan dan penegak hukum karena posisi penyalahguna narkotika yang secara formal berada pada dua dimensi, yaitu dimensi kesehatan dan dimensi hukum. Penyalahguna narkotika merupakan seorang pelaku kriminal yang diancam pidana, di sisi lain penyalahguna narkotika merupakan "orang sakit" yang wajib direhabilitasi agar dapat pulih. Selama ini, dimensi penegakan hukum cenderung lebih sering dilakukan, dengan indikasi pemberlakuan hukuman penjara (lapas) tanpa akses rehabilitasi kepada penyalahguna narkotika yang tertangkap menggunakan narkotika untuk diri sendiri ${ }^{8}$.

Pelaksanaan pembinaan maupun program rehabilitasi masih sangat tergantung kondisi lapas maupun lapasustik masingmasing dan masih banyak persoalan yang terjadi, sehingga

${ }^{8}$ Iskandar, A. Jalan lurus: Penanganan Penyalahguna Narkotika dalam Konstruksi Hukum Positif (Karawang : CV. Viva Tanpas, 20I5). 
efektivitasnya masih belum bisa dipastikan. Hal tersebut membuat tidak semua narapidana yang bebas menjadi jera dan menjadi lebih baik, sehingga potensi risiko menjadi residivis besar. Jackson mengatakan bahwa tingkat residivis merupakan indikator efektivitas pidana penjara9. Suatu pidana adalah efektif apabila si pelanggar tidak dipidana lagi dalam suatu periode tertentu. Efektivitas adalah suatu pengukuran dari perbandingan antara jumlah pelanggar yang dipidana kembali dan yang tidak dipidana kembali.

Beberapa penelitian tentang peran faktor lingkungan Lapas pada residivisme, seperti McKiernan, dkk ${ }^{10}$, Woessner \& Schwedler ${ }^{11}$, Cochran ${ }^{12}$, Evans, Huang, \& Hser ${ }^{13}$, Listwan, Sundt, \& Holsinger ${ }^{14}$, Baro ${ }^{15}$, Wilson, Bouffard, \& Mackenzie ${ }^{16}$, antara lain melihat metode rehabilitasi, treatment correctional yang meliputi perubahan terapeutik dan iklim penjara, dukungan sosial selama masa pemenjaraan, dampak lama pemenjaraan, karakteristik treatmen yang diterima selama pemenjaraan, pengaruh program

\footnotetext{
9 Barda Nawawi Arief, Bunga Rampai Kebijakan Hukum Pidana, Perkembangan Penyusunan Konsep KUHP Baru, (Jakarta: Kencana, 20 I 0), hal. 2I4. Sebagaimana dikuti dari: Rifanly Potabuga, "Pidana Penjara Menurut KUHP", Lex Crimen Vol.I, No.4, Okt-Des, 20I2, hal. 79-93.

10 McKiernan,P., Shamblen,SR., Collins,DA., Strader,TN., \& Kokoski, C. "Creating Lasting Family Connections: Reducing Recidivism with Community-Based Family Strengthening Model". Criminal Justice Policy Review. 24(I).(2013), 94-122

$1 "$ Woessner, G \& Schwedler, A. "Correctional Treatment of Sexual and Violent Offenders: Therapeutic Change, Prison Climate, and Recidivism". Criminal Justice and Behavior. Published online (I3 February 20 I4). doi: I0.1 I77/00938548 I3

${ }^{12}$ Cochran, J.C. "Breaches in the Wall : Imprisonment, Social Support, and Recidivism". Journal of Research in Crime and Delinquency. 5 I (2) (2014), 200-229.

13 Evans, E., Huang, D., Hser, Y.I. "High Risk Offenderes Partisipating in Court-Supervised Substance Abuse Treatment : Characteristic, Treatment Received, \& Factors Associated with Recidivism". Journal of Behavioral Health Service \& Research, 38(4) (Oktober, 20I I), 5I 0-525

14 Listwan, S.J., Sundt, J.L., \& Holsinger, A.M. "The Effect on Drug Court Programming on Recidivism: The Cincinati Experience". Crime \& Delinquency, 49(3), (Juli, 2003) 389-4I I. doi: | 0.1 | 777/00 | | | 28703253762 .

${ }^{15}$ Baro, A.L. "Effect of Cognitive Restructuring Program on Inmate Institutional Behavior". Criminal Justice \& Behavior. American Association for Correctional Psychology, 26(4), (Desember, 1999), 466-484

${ }^{16}$ Wilson, D.B., Bouffard, L.A., \& Mackenzie, D.L. "A Quantitative Review of Structured, GroupOriented, Cognitive-Behavioral Programs for Offenders". Criminal Justice And Behavior. American Association for Correctional Psychology, 32(2), (April, 2005), 172-204, doi: 10.1 177/0093854804272889,
} 
pengadilan narkoba pengaruh program restrukturisasi kognitif, pengaruh program kognitif behavioral pada residivisme.

Penelitian-penelitian tersebut dilakukan pada residivis non narkoba, maupun narapidana narkoba, serta dilakukan di luar Indonesia, sementara Indonesia memiliki konteks sistem hukum yang berbeda dengan konteks hukum pada penelitian tersebut. Di Indonesia, penulis menemukan beberapa penelitian yang dilakukan antara lain oleh Maspidah ${ }^{17}$, Jumarni ${ }^{18}$, Putra ${ }^{19}$ tentang peran lapas maupun lapasustik pada pembinaan narapidana narkoba, penelitian peran lapas dalam membina narapidana penyalahgunaan narkotika ditinjau dari fiqh siyasah ${ }^{20}$, serta pengaruh terapi kognitif perilaku pada kontrol diri residivis ${ }^{21}$, namun penelitian tersebut dilakukan bukan pada residivis narkoba. Sementara, residivis narkoba, khususnya pengguna memiliki kekhasan bila dibandingkan dengan residivis secara umum yang lain, oleh karena itu penelitian ini dilakukan dengan tujuan untuk memahami peran lapas dan lapasustik pada residivis narkoba pengguna, sebagai implementasi dari UU No. 12 Tahun 1995 tentang Pemasyarakatan dan UU. No. 35 Tahun 2009 tentang narkotika. Secara khusus, tujuan penelitian ini adalah mengetahui bagaimana proses pembinaan di lapas maupun lapasustik pada residivis narapidana pengguna, dan mengetahui efektivitas pembinaan tersebut.

\footnotetext{
17 Maspidah, "Peran Lembaga Pemasyarakatan Narkotika Klas IIA Sungguminasa dalam Pembinaan Narapidana" (Tesis -- Program Pasca Sarjana Universitas Negeri Makasar, 20 I9).

18 Jumarni, "Peran Lembaga Pemasyarakatan Kelas II A Watampone dalam Pembinaan Narapidana Penyalahgunaan Narkoba Berdasarkan Undang-Undang Nomor 12 Tahun 1995 tentang Pemasyarakatan". Jurnal Al-Dustur, Volume 2 No 2, (Desember, 2019)

19 Putra, RA. "Peranan Lembaga Kemasyarakatan dalam Pembinaan Narapidana Penyalahgunaan Narkotika (Studi di Lembaga Pemasyarakatan Klas IIA Sragen). (Tesis -- Fakultas Hukum Universitas Muhamadiyah, Surakarta, 2013)

${ }^{20}$ Riyan. "Peran Lembaga Pemasyarakatan dalam Membina Narapidana Penyalahgunaan Narkotika Menurut Uu Nomor 12 Tahun 1995 Ditinjau dari Figh Siyasah (Studi pada Lembaga Pemasyarakatan Kelas I Bandar Lampung)" (Skripsi - Universitas Islam Negeri Raden Intan, Lampung, 2019)

${ }^{21}$ Yusuf, U \& Raissa, P. "Pengaruh Terapi Kognitif Perilaku terhadap Peningkatan Kontrol Diri pada Residivis". Jurnal Intervensi Psikologi). 3(2). (201 I). Diakses dari database portal Garuda
} 


\section{Metode Penelitian}

Penelitian ini adalah penelitian kualitatif dengan pendekatan studi kasus. Metode pengambilan data menggunakan wawancara dan observasi. Metode analisis data mengkombinasi tahapan analisis dari Morse ${ }^{22}$ dan Miles dan Huberman ${ }^{23}$. Teknik purposive sampling digunakan, dengan kriteria subjek penelitian, yaitu : residivis narkoba pengguna; pernah mengalami lapas maupun lapasustik; berusia dewasa secara hukum ( $\geq 18$ tahun); dengan kasus pasal 127 UU No. 35 Tahun 2009 tentang Narkotika atau pasal 36 UU No 5 Tahun 1997 tentang Psikotropika maupun junto dengan pasal-pasal yang lain; klasifikasi BI dan BIIa (dijatuhi hukuman di atas 4 bulan); berada pada tingkat penggunaan narkoba 1-4 menurut Costigan, Crofts, \& Reid, yaitu : tingkat cobacoba, sosial/rekreasional, tergantung pada keadaan/situasional, dan intensif ${ }^{24}$. Jumlah subjek dalam penelitian ini adalah 8 orang residivis narkoba pengguna.

Secara umum karakterisitik umum yang ada pada subjek penelitian nampak pada tabel 1 di bawah ini:

Tabel 1. Karakteristik Subjek

\begin{tabular}{|c|c|c|c|c|c|}
\hline No & Inisial & $\begin{array}{l}\text { Preferensi } \\
\text { Pemakaian }\end{array}$ & Masuk Lapas & Vonis & Pasal Kasus \\
\hline 1. & Baru & $\begin{array}{ll}\text { Shabu } \quad \& \\
\text { ekstasi; } \\
\text { Sendiri }\end{array}$ & $\begin{array}{l}3 \text { kali, } \\
\text { Lapas } 2 x \\
\text { Lapasustik 1x }\end{array}$ & $\begin{array}{l}4 \text { th } 3 \mathrm{bl} \\
1 \text { th } 8 \mathrm{bl} \\
1 \text { th }\end{array}$ & $\begin{array}{l}127 \quad \text { (1a) \& } \\
112 \\
127(1 a) \\
127(1 a)\end{array}$ \\
\hline 2. & Tenu & $\begin{array}{l}\text { Shabu; } \\
\text { Bersama }\end{array}$ & $\begin{array}{l}2 \text { kali } \\
\text { Rutan 1x } \\
\text { Lapasustik 1x }\end{array}$ & $\begin{array}{l}4 \mathrm{bl} \\
1 \text { th } 3 \mathrm{bl}\end{array}$ & $\begin{array}{l}127(1 \mathrm{a}) \\
127(1 \mathrm{a})\end{array}$ \\
\hline 3. & Wali & $\begin{array}{l}\text { Shabu, lanjut } \\
\text { ganja; } \\
\text { Sendiri }\end{array}$ & $\begin{array}{l}4 \text { kali } \\
\text { Lapas 2x } \\
\text { Lapasustik 2x }\end{array}$ & $\begin{array}{l}1 \text { th } 6 \mathrm{bl} \\
1 \text { th } 5 \mathrm{bl} \\
11 \mathrm{bl}\end{array}$ & $\begin{array}{l}127(1 \mathrm{a}) \\
127(1 \mathrm{a}) \\
127(1 \mathrm{a})\end{array}$ \\
\hline
\end{tabular}

\footnotetext{
22 Morse, J. M. Designing Funded Qualitative Research. In N. K. Denzin \& Y. S. Lincoln (Eds.), Handbook of Qualitative Research, (California: Sage Publications, Inc 1994). 220-235..

${ }_{23}$ Miles, M.B and Huberman, A.. Qualitative Data Analysis, A Sourcebook of New Method. (California: Sage Publication, 1994)

${ }^{24}$ Costigan, G, Crofts N, \& Reid G. Pedoman Mengurangi Dampak Buruk Narkoba di Asia. Edisi Indonesia. Yogyakarta: Warta AIDS, 200I).
} 


\begin{tabular}{|c|c|c|c|c|c|}
\hline & & & & 1 th $2 \mathrm{bl}$ & 127 (1a) \\
\hline 4. & Riyan & $\begin{array}{l}\text { Ganja; } \\
\text { Bersama }\end{array}$ & $\begin{array}{l}2 \text { kali } \\
\text { Lapasustik }\end{array}$ & $\begin{array}{l}1 \text { th } \\
1 \text { th } 4 \text { bl }\end{array}$ & $\begin{array}{l}127(1 \mathrm{a}) \\
127(1 \mathrm{a}) \\
\end{array}$ \\
\hline 5. & Wita & $\begin{array}{l}\text { Shabu \& inex } \\
\text { Sendiri }\end{array}$ & $\begin{array}{l}3 \text { kali, } \\
\text { Lapas 1x } \\
\text { Lapasustik 2x }\end{array}$ & $\begin{array}{l}1 \text { th } 6 \mathrm{bl} \\
4 \text { th } 3 \mathrm{bl} \\
1 \text { th } 8 \mathrm{bl}\end{array}$ & $\begin{array}{l}127(1 \mathrm{a}) \\
127 \quad \text { (1a) \& } \\
112(1) \\
127(1 \mathrm{a})\end{array}$ \\
\hline 6. & Rapu & $\begin{array}{l}\text { Ganja; } \\
\text { Bersama }\end{array}$ & $\begin{array}{l}2 \text { kali, } \\
\text { Lapas 1x } \\
\text { Lapasustik 1x }\end{array}$ & $\begin{array}{l}1 \text { th } 6 \mathrm{bl} \\
5 \text { th }- \\
\text { kasasi: } 1 \\
\text { th } 6 \mathrm{bl}\end{array}$ & $\begin{array}{l}127(1 \mathrm{a}) \\
127 \quad(1 \mathrm{a}) \\
112(1)\end{array}$ \\
\hline 7. & Fly & $\begin{array}{l}\text { Shabu; } \\
\text { Sendiri }\end{array}$ & $\begin{array}{l}2 \text { kali } \\
\text { Lapas 1x } \\
\text { Lapasustik 1x }\end{array}$ & $\begin{array}{l}6 \mathrm{bl} \\
1 \text { th } 7 \mathrm{bl}\end{array}$ & $\begin{array}{l}127(1 \mathrm{a}) \\
127(1 \mathrm{a})\end{array}$ \\
\hline 8. & Wiwi & $\begin{array}{l}\text { Ganja; } \\
\text { Bersama }\end{array}$ & $\begin{array}{l}2 \text { kali, } \\
\text { Lapasustik 2x }\end{array}$ & $\begin{array}{l}4 \text { th } 10 \mathrm{bl} \\
10 \mathrm{bl}\end{array}$ & $\begin{array}{ll}127 \quad(1 a) \quad \& \\
144 \\
127(1 a)\end{array}$ \\
\hline
\end{tabular}

Peran Lapas dan Lapasustik pada Residivis Narkoba Pengguna sebagai Implementasi UU No. 12 Tahun 1995 tentang Pemasyarakatan dan UU. No. 35 Tahun 2009 tentang Narkotika.

Peran menurut Soekanto ${ }^{25}$ adalah suatu aspek dinamis dari status sosial atau kedudukan. Peran lebih mengedepankan fungsi penyesuaian diri dan sebagai sebuah proses. Peran mencakup tiga hal, yaitu: (1) Peran merupakan bagian dari peraturan (normanorma) yang membimbing seseorang di dalam masyarakat. (2) Peran adalah sesuatu yang seharusnya dilakukan individu di dalam suatu masyarakat. (3) Peran adalah perilaku individu yang memiliki peranan penting di dalam struktur sosial masyarakat. Konteks penelitian ini, lapas maupun lapasustik yang memiliki peran bagi residivis narkoba.

\section{Dasar Hukum Peran Lapas dan Lapasustik pada Residivis Narkoba Pengguna}

${ }^{25}$ Soerjono Soekanto. Sosiologi Suatu Pengantar. (Jakarta : Rajawali Pers, 2009). 
Lembaga pemasyarakatan (lapas) merupakan salah satu sub sistem dari sub sistem sub sistem lainnya seperti kepolisian, kejaksaan, dan pengadilan. Lapas merupakan tahapan akhir dari sistem peradilan pidana. Lapas memiliki peran penting dan menyeluruh karena merupakan institusi dari sub sistem peradilan pidana yang mempunyai fungsi strategis sebagai pelaksanaan pidana penjara sekaligus sebagai tempat pembinaan bagi narapidana. Posisi lapas dalam konteks sistem peradilan pidana dan perannya sebagai lembaga pembinaan sangat strategis dalam merealisasikan tujuan akhir dari sistem peradilan pidana, yaitu resosialisasi dan rehabilitasi pelanggar hukum, bahkan sampai kepada penanggulangan kejahatan.

Pelaksanaan pidana penjara dengan sistem pemasyarakatan mengacu kepada Undang-undang Nomor 12 Tahun 1995 tentang pemasyarakatan, di mana fungsi pemidanaan tidak lagi sekedar penjeraan tetapi juga merupakan suatu rehabilitasi dan reintegrasi sosial. Hal tersebut nampak pada tujuan pemasyarakatan pasal 2 Undang-Undang No. 12 Tahun 1995 tentang Pemasyarakatan, yaitu: "agar menyadari kesalahan, memperbaiki diri dan tidak mengulangi tindak pidana sehingga dapat diterima kembali oleh lingkungan masyarakat, dapat berperan aktif dalam pembangunan dan dapat hidup secara wajar sebagai warga yang baik dan bertanggung jawab".

Pemasyarakatan merupakan suatu proses pembinaan narapidana yang sering disebut sebagai therapeutic process. Sistem pembinaan pemasyarakatan sebagaimana disebutkan pada pasal 5 Undang-undang No. 12 tahun 1995 tentang Pemasyarakatan, bahwa sistem pembinaan pemasyarakatan dilaksanakan berdasarkan asas-asas pembinaan, yaitu: pengayoman, persamaan perlakuan dan pelayanan, pendidikan dan pembimbingan, penghormatan harkat dan martabat manusia, kehilangan kemardekaan merupakan satu-satunya penderitaan, terjaminnya 
hak untuk tetap berhubungan dengan keluarga dan orang-orang tertentu ${ }^{26}$.

Tujuan pembinaan yang dilakukan oleh lapas selaras dengan tujuan pemasyarakatan, yaitu agar narapidana tidak mengulangi lagi perbuatannya dan bisa menemukan lagi kepercayaan dirinya, serta dapat diterima menjadi bagian dari anggota masyarakat. Berdasarkan penjelasan pasal 7 UU No. 12 tahun 1995 tentang Pemasyarakatan, pembinaan dan pembimbingan WBP meliputi program pembinaan dan bimbingan yang berupa kegiatan pembinaan kepribadian dan kegiatan pembinaan kemandirian. Pembinaan kepribadian diarahkan pada pembinaan mental dan watak agar WBP menjadi manusia seutuhnya, bertakwa, dan bertanggung jawab kepada diri sendiri, keluarga, dan masyarakat. Sedangkan pembinaan kemandirian diarahkan pada pembinaan bakat dan keterampilan agar WBP dapat kembali berperan sebagai anggota masyarakat yang bebas dan bertanggung jawab.

Menurut pasal 12 UU No. 12 tahun 1995 tentang Pemasyarakatan, dalam rangka pembinaan narapidana di lapas dilakukan penggolongan narapidana berdasarkan: a) umur, b) jenis kelamin, c) lama pidana yang dijatuhkan, d) jenis kejahatan, dan e) kriteria lainnya sesuai dengan kebutuhan atau perkembangan pembinaan. Sesuai dengan penggolongan tersebut, narapidana narkotika secara khusus residivis narkoba pengguna memerlukan pembinaan secara lebih komprehensif dan berkelanjutan karena selain dikatakan sebagai pelanggar hukum, mereka juga dikatakan sebagai orang yang sakit akibat penggunaan narkotika. Suthon ${ }^{27}$ menyatakan bahwa kejahatan penyalahgunaan narkotika merupakan kejahatan serius yang membahayakan masyarakat, untuk itu diperlukan mekanisme kontrol sosial dan sistem penghukuman yang tepat guna mengendalikan kejahatan tersebut.

${ }^{26}$ Dwija Priyatno, Sistem Pelaksanaan Pidana Penjara di Indonesia. (Bandung: PT. Refika Aditama, 2006).

27 Pratt, John \& Brown, Mark., Dangerous Offender. Punishment and Social Order. USA : Routledge, 2000) 
Dengan kata lain, kejahatan narkotika merupakan extraordinary crime yang memerlukan penanganan khusus dan maksimal.

Penyalahgunaan narkotika dan psikotropika merupakan persoalan yang kompleks karena terkait dengan proses hukum, yaitu tindak pidana pelanggaran UU No 35 tahun 2009 tentang narkotika dan UU No 5 tahun 1997 tentang psikotropika, di sisi lain adalah korban penyalahgunaan narkotika dan psikotropika wajib menjalani rehabilitasi. Pada Undang-Undang Nomor 35 Tahun 2009 tentang Narkotika pasal 54 menyatakan bahwa: Pecandu narkotika dan korban penyalahgunaan narkotika wajib menjalani rehabilitasi medis dan rehabilitasi sosial. Pasal 103 Undang-Undang Nomor 35 Tahun 2009 tentang Narkotika menyebutkan bahwa hakim yang memeriksa perkara pecandu narkotika dapat memutus dan menetapkan yang bersangkutan baik yang terbukti bersalah maupun tidak untuk menjalani pengobatan dan/atau perawatan melalui rehabilitasi.

Pelaksanaan program rehabilitasi yang dilakukan di Lembaga Pemasyarakatan maupun rumah Tahanan, pelaksanaannya disesuaikan dengan pembinaan yang mengacu pada Keputusan Menteri Kehakiman RI Nomor: M.02-PK.04.10 tanggal 10 April 1990 tentang Pola Pembinaan Narapidana dan Tahanan. Pada tahun 2017, Menteri Hukum dan HAM menerbitkan Permenkumham Nomor 12 Tahun 2017 Tentang Rehabilitasi Narkotika Bagi Tahanan dan Warga Binaan Pemasyarakatan sebagai dasar penyelenggaraan rehabilitasi di UPT Pemasyarakatan.

Pembinaan terhadap narapidana narkotika termasuk residivis narkoba pengguna saat ini didasarkan pada data putusan pengadilan yang mengklasifikasikan narapidana narkotika ke dalam 3 kategori, yakni: pengguna, pengedar, dan bandar. Klasifikasi ini belum diyakini sesuai dengan fakta materiil di lapangan, tapi hanya klasifikasi administratif. Untuk itu diperlukan asesmen yang mendalam terhadap narapidana narkotika untuk mengetahui sejauh mana sesungguhnya keterlibatan mereka dalam penyalahgunaan narkotika. Ada indikasi bahwa seseorang yang 
secara administratif diklasifikasikan sebagai pengguna akan tetapi sebenarnya mereka mempunyai klasifikasi sebagai pengedar atau bandar dan sebaliknya. Hal ini tentu saja berkorelasi dengan tingkat pengamanan terhadap mereka ${ }^{28}$. Pembinaan terhadap narapidana narkotika khususnya penyalahgunaan pada umumnya lebih diintensifkan pada bidang kesehatan, khususnya yang mengalami ketergantungan. Adapun perawatan kesehatan WBP narkotika antara lain: a) kegiatan perawatan kesehatan secara umum, b) kegiatan perawatan ketergantungan narkotika, c) kegiatan perawatan kesehatan jasmani, d) kegiatan perawatan kesehatan mental dan rohani. Pembinaan terhadap narapidana narkotika termasuk residivis narkoba pengguna tersebut dilakukan di lapas maupun lapasustik.

Secara umum lapas maupun lapasustik sama-sama melaksanakan fungsi pemasyarakatan, namun lapasustik memiliki karakteristik maupun kondisi yang berbeda. Lapas khusus narkotika (Lapasustik) menurut Sasangka ${ }^{29}$ merupakan lembaga khusus yang diperuntukkan bagi narapidana kasus narkotika, berdiri sendiri dengan pola pembinaan berbeda dengan lapas, yaitu menggunakan aspek penanganan dan pendekatan yang meliputi aspek perawatan dan aspek kesehatan narapidana. Lapasustik ini memiliki bentuk bangunan yang sangat spesifik dengan tingkat pengamanan maksimum (Maximum Security Prison) dan tingkat pengamanan yang super maksimum (Super maximum-security prison) yang dimaksudkan untuk memberikan pembinaan dan rehabilitasi bagi narapidana kasus narkotika ${ }^{30}$.

Implementasi UU No. 12 Tahun 1995 tentang Pemasyarakatan dan UU. No. 35 Tahun 2009 tentang Narkotika di Lapas dan Lapasustik

\footnotetext{
${ }^{28}$ Laporan Kegiatan Pengkajian Hak Manusia di Wilayah Karakteristik Narapidana Kasus Narkotika oleh Bidang Hak Asasi Manusia Divisi Pelayanan Hukum dan HAM Kantor Wilayah Kementrian Hukum dan HAM DKI Jakarta tahun 2019

${ }^{29}$ Hari Sasangka. Narkotika dan Psikotropika dalam Hukum Pidana. (Bandung: Mandar Maju, 2003).

${ }^{30}$ Laporan Kegiatan Pengkajian Hak Manusia di Wilayah Karakteristik Narapidana Kasus Narkotika oleh Bidang Hak Asasi Manusia Divisi Pelayanan Hukum dan HAM Kantor Wilayah Kementrian Hukum dan HAM DKI Jakarta tahun 2019
} 
Pada penelitian ini hampir semua subjek pernah menjalani pemidanaan di lapas maupun lapasustik, kecuali dua subjek yang menjalani pemidanaan hanya di lapasustik, meski demikian keduanya pernah mengalami proses pemidanaan di Rumah Tahanan (Rutan) yang juga melakukan fungsi pemasyarakatan seperti lapas, sehingga para residivis narkoba pengguna tersebut memahami peran lapas maupun lapasustik.

Hasil penelitian ini menunjukkan bahwa lapas maupun lapasustik sama-sama dipersepsikan membuat subjek mengalami kecemasan dan kekuatiran akan apa yang akan terjadi selama di lapas, khususnya pada pemidanaan pertama namun pada pemidanaan selanjutnya subjek menjadi lebih tenang karena sudah punya bayangan dan sudah dapat menyesuaikan diri dengan kondisi lapas maupun lapasustik. Kemampuan penyesuaian diri ini menurut Schneiders ${ }^{31}$ adalah usaha yang mencakup respon mental dan tingkah laku individu, yaitu individu berusaha keras agar mampu mengatasi konflik dan frustrasi karena terhambatnya kebutuhan dalam dirinya, sehingga tercapai keselarasan dan keharmonisan dengan diri atau lingkungannya. Penyesuaian diri ini diperlukan supaya tidak memunculkan konflik dan frustrasi dalam diri residivis narkoba tersebut.

Subjek yang mengalami pemidanaan di lapas maupun lapasustik mempersepsikan bahwa kedua lapas tersebut memiliki karakteristik yang berbeda, khususnya dalam hal kasus yang membuat Warga Binaan Pemasyarakatan (WBP) masuk ke dalam lapas, sikap petugas terhadap WBP, kegiatan pembinaan dan program rehabilitasi. Lapas memiliki WBP yang cenderung heterogen karena bervariasi kasusnya, sementara Lapasutik cenderung homogen WBP-nya, pada penelitian ini yaitu kasus narkoba, meski sebenarnya dalam kasus narkoba dibedakan antara pengguna, pengedar, dan bandar. Pada lapas terdapat perbedaan sikap petugas kepada WBP kasus narkoba maupun kasus yang lain. Petugas lapas akan cenderung bersikap lebih keras pada kasus

${ }^{31}$ Schneiders, A.A. Personal Adjustment and Mental Health. New York: Holt, Reinhart and Winston Inc, 1999). 
kriminal khususnya pada kasus pencabulan, daripada kasus narkoba, sementara di lapasustik petugas cenderung memperlakukan WBP secara sama, namun cenderung lebih humanis, sehingga WBP merasakan kenyamanan selama berada di lapasustik, bila dibandingkan dengan di lapas.

Perbedaan sikap petugas terhadap WBP di lapas ini dapat membuat stratifikasi sosial dalam lapas, dimana stratifikasi sosial merupakan suatu sistem kelompok manusia terbagi dalam lapisanlapisan sesuai dengan kekuasaan, kepemilikan, dan prestise relatif mereka $^{32}$. Stratifikasi sosial ini merupakan sebuah konsep yang menunjukkan adanya pembedaan dan/atau pengelompokan suatu kelompok sosial (komunitas) secara bertingkat, didasarkan pada adanya suatu simbol-simbol tertentu yang dianggap berharga atau bernilai secara sosial, ekonomi, politik, hukum, budaya maupun dimensi lainnya dalam suatu kelompok sosial (komunitas). Strata sosial ini dapat diperoleh dengan tiga hal yaitu, previllage, prestise dan power $^{33}$. Hal ini sesuai dengan hasil penelitian Kartikawati ${ }^{34}$ yang menunjukkan bahwa di Rutan Pondok Bambu terjadi stratifikasi sosial, dimana jenis kasus tindak pidana korupsi (tipikor) maupun kasus narkoba khususnya pengedar berada pada lapisan atas, sementara kasus penggelapan berada pada lapisan tengah, serta kasus pembunuhan, pencurian, dan penipuan berada pada lapisan bawah. Pelapisan sosial di Rutan Pondok Bambu ini dalam batas tertentu terbentuk dari penyimpangan aturan kekuasaan, dan wewenang dari petugas rutan selaku petugas teknis aturan hukum. Hal tersebut yang secara tidak langsung menyebabkan pembedaan-pembedaan dalam kehidupan warga binaan rutan yang kemudian "membudaya", sehingga membentuk stratifikasi sosial.

Hasil penelitian menunjukkan bahwa perbedaan sikap petugas terhadap WBP di lapas ini dapat membuat WBP tersebut

\footnotetext{
32 James M. Henslin, Sosiologi dengan Pendekatan Membumi. (Jakarta: Erlangga, 2006)..

33 Max Weber, Sosiologi. (Yogyakarta: Pustaka Pelajar, 2006).

${ }^{34}$ Kartikawati, Reni. "Stratifikasi Sosial Warga Binaan Wanita di Rutan Pondok Bambu". Jurnal Sosiologi Masyarakat, Vol. I7, No. 2, (Juli 20 I2), 153-I86.
} 
memiliki persepsi yang keliru bahwa narapidana narkoba (termasuk residivis narkoba pengguna) berbeda dengan narapidana kriminal yang lain. Bagi residivis narkoba pengguna, mereka adalah korban, tidak merugikan orang lain, berbeda dengan narapidana kriminal yang memiliki karakteristik negatif. Hal tersebut menunjukkan bahwa terjadi kesalahan-kesalahan atau kesesatankesesatan di dalam berpikir yang menurut Beck dan Weishaar disebut sebagai bias/distorsi kognitif ${ }^{35}$. Bias/distorsi kognitif pada subjek dalam penelitian ini, menurut Beck dan Weishaar termasuk dalam jenis bias/distorsi inferensi arbiter (arbitrary inference), yaitu menarik kesimpulan yang merupakan inferensi dari bukti-bukti yang tidak relevan. Selain itu, residivis narkoba juga mengalami self serving bias, yaitu salah satu dari kesalahan dalam atribusi (menilai perilaku). Self serving bias ini merupakan kesalahan atribusi yang disebabkan orang cenderung membenarkan diri sendiri, mengutamakan diri sendiri untuk mempertahankan dan meningkatkan harga diri. Bias yang mementingkan diri sendiri sangat terbukti ketika individu merumuskan atribusi tentang penyebab dari tindakan pribadi, peristiwa, dan hasil. Ketika menjelaskan tindakan dan pengalaman positif, atribusi mereka menekankan dampak sebab dari internal, penyebab disposisi, tetapi ketika mengidentifikasi penyebab peristiwa negatif, mereka menekankan faktor eksternal, yaitu situasi atau pihak lain di luar dirinya ${ }^{36}$.

Pelanggaran moral atau norma setelah menggunakan narkoba yang membuat mereka harus berhadapan dengan hukum dan dipidana, namun hal tersebut tidak membuat subjek mengalami self contempt (menyalahkan diri sendiri/jijik pada diri sendiri). Hal ini disebabkan antara lain karena sikap petugas di lapasustik yang cenderung lebih humanis sehingga membuat

\footnotetext{
${ }^{35}$ Beck, A. T., \& Weishaar, M. E. Cognitive Therapy. In A. Freeman, K. M. Simon, L. E. Beutler, \& H. Arkowitz (Eds.), Comprehensive Handbook of Cognitive Therapy. (Plenum Press, 1989), $21-$ 36.

${ }^{36}$ Robert, A. Baron \& Nyla, R. Branscombe. Social Psychology. USA : Pearson Education, Inc, 20I2).
} 
mereka nyaman selama di lapasustik. Menurut Bandura ${ }^{37}$, seseorang bisa melakukan pelanggaran moral tanpa mengalami selfcontempt dengan mengembangkan suatu mekanisme tertentu. Penelitian ini menunjukkan bahwa mekanisme yang dikembangkan oleh subjek sama seperti dugaan awal penulis, yaitu: a). Perbandingan yang menguntungkan (Advantageous Comparison), yaitu seseorang membandingkan perilaku pelanggaran moral dengan pelanggaran lain yang lebih berat, sehingga orang tersebut bisa membenarkan diri. b). Pengabaian atau distorsi konsekuensi (Disregard or distortion of consequences), yaitu seseorang mengabaikan bahaya yang akan ditimbulkan dari perbuatannya. dan c). Atribusi kesalahan (Attribution of blame), yaitu seseorang menyalahkan pihak lain atas pelanggaran moral yang telah diperbuatnya. Pengalaman dipidana di lapas maupun lapasustik ini membuat residivis narkoba tidak memiliki self contemt dan tidak jera.

Salah satu tujuan pemidanaan pada lapas adalah rehabilitasi, yaitu dengan adanya pemidanaan diharapkan terdapat koreksi terhadap terpidana dan dengan demikian menjadikannya orang yang baik dan berguna, serta mampu hidup bermasyarakat, tetapi pada kenyataannya tidak semua terpidana yang bebas menjadi jera dan bertobat menjadi lebih baik. Secara khusus untuk kasus narkoba, negara Indonesia menganut double track system pemidanaan sesuai dengan UU No. 35 tahun 2009 tentang narkotika, maka mereka yang melakukan penyalahgunaan narkotika dapat dihukum pidana dan dapat dihukum rehabilitasi atau dihukum pidana dan ditambah hukuman rehabilitasi (Pasal 36 UU No. 8 tahun 1976 dan Pasal 103 UU No. 35 tahun 2009). Selama ini kebijakan legal terkait rehabilitasi penyalahguna narkotika masih belum sepenuhnya terimplementasi dengan baik. Hal ini akibat adanya tarik menarik di antara para pengambil kebijakan di bidang kesehatan dan penegak hukum terkait cara penanganan penyalahguna narkotika untuk diri sendiri. Selama ini, dimensi

37 Bandura, A. The Self System in Reciprocal Determinism. American Psychologist. 44(9), (1978), II75-1 I84 
penegakan hukum cenderung lebih sering dilakukan Hal ini menunjukkan tidak adanya keseimbangan antara dimensi kesehatan dan dimensi hukum dalam double track system pemidanaan terhadap penyalahguna narkotika. Hal tersebut kemungkinan besar dapat berdampak yang kurang positif bagi penyalahguna narkotika, karena dimensi hukum tidak dapat menyelesaikan persoalan personal para penyalahguna narkotika khususnya yang terkait dengan ketergantungan terhadap narkoba, sehingga peluang mereka akan menggunakan narkoba lagi masih besar.

Penelitian ini menunjukkan bahwa residivis narkoba mempersepsikan kegiatan pembinaan di lapas maupun lapasustik cenderung sama, kecuali di rutan yang cenderung terbatas dalam hal fasilitas maupun sarana prasarana. Lapas maupun lapasustik mengadakan program rehabilitasi, namun program rehabilitasi di lapasustik cenderung lebih baik, lebih terencana dan lebih terorganisir bila dibandingkan di lapas, namun rehabilitasi yang dilakukan di lapas maupun lapasustik belum dipandang efektif untuk menyelesaikan persoalan para penyalahguna narkoba.

Program rehabilitasi yang selama ini dilakukan di lapas maupun lapasustik bekerja sama dengan Badan Narkotika Nasional (BNN). Program rehabilitasi ini dilakukan dengan menggunakan model Therapeutic Community (TC). Therapeutic Community sendiri merupakan suatu program rehabilitasi bagi pecandu narkoba dengan membentuk suatu komunitas positif dalam lingkungan teratur dan terkoordinir dengan kegiatan-kegiatan yang menunjang perubahan secara fisik maupun mental yang mana di dalam komunitas ini para pecandu narkoba diberikan sistem terapi yang bersifat membangun dan mandiri, agar mereka bisa belajar untuk lepas dari ketergantungan terhadap zat adiktif dan juga untuk menghilangkan kebiasaan-kebiasaan negatif yang telah diperoleh semasa mereka menjadi pecandu aktif. Selain itu, di lapasustik juga dilaksanakan rehabilitasi medis yang merupakan prosedur bagi seorang pecandu diberikan perawatan medis untuk menjauhkan atau menghilangkan ketergantungan terhadap zat. Rehabilitasi 
medis adalah suatu proses kegiatan pengobatan secara terpadu untuk membebaskan pecandu dari ketergantungan narkotika, psikotropika dan zat adiktif lainnya (Buku Program Rehabilitasi Modalitas Therapeutic Community Lapas Narkotika Klas IIA Yogyakarta, 1 Oktober 2015).

Program rehabilitasi tersebut masih dianggap oleh semua subjek belum efektif untuk membuat mereka tidak menggunakan narkoba setelah keluar dari lapas maupun lapasustik. Program rehabilitasi tersebut lebih bermanfaat bagi subjek untuk mengisi waktu luang dan bersifat penyegaran (refreshing). Sebagian besar subjek merasa kegiatan pembinaan keagamaan cenderung lebih efektif dibandingkan dengan program rehabilitasi. Persepsi subjek terhadap lapas maupun lapaustik tersebut akan memperkuat bias/distorsi kognitif tentang pandangan bahwa WBP kasus narkoba berbeda dengan WBP kasus kriminal lain dan pandangan bahwa lapas maupun lapasustik tidak akan membuat subjek jera untuk memakai narkoba. Ketidakefektifan rehabilitas di lapas maupun lapasustik selama ini dimungkinkan karena intervensi dalam program rehabilitasi narkoba belum menyentuh sisi kebutuhan personal yang mendasar dalam diri WBP.

Berdasarkan pengamatan dan wawancara terhadap subjek, maupun pihak-pihak yang berkepentingan di lapas maupun lapasustik, disimpulkan bahwa kondisi lapasustik cenderung lebih baik/kondusif bagi residivis narkoba pengguna bila dibandingkan dengan kondisi di lapas. Kesimpulan ini didasarkan pertimbangan bahwa lapasustik memang dikhususkan bagi WBP kasus narkoba. Kesamaan kasus ini akan memudahkan perlakuan terhadap WBP dan meminimalkan WBP untuk belajar tindak kejahatan yang lainnya karena tidak digabung dan melakukan kontak dengan kasus yang lain. Selain itu, program rehabilitasi yang diadakan di lapasustik cenderung lebih terencana dan terkoordinasi dengan lebih baik, dibandingkan dengan di lapas, namun supaya program rehabilitasi dapat lebih efektif dirasakan oleh WBP untuk membuat mereka tidak kembali lagi ke narkoba perlu mempertimbangkan 
kebutuhan masing-masing WBP secara personal yang membuat WBP menggunakan narkoba.

Lapas maupun lapasustik merupakan konteks lingkungan residivis narkoba pengguna dalam penelitian ini. Teori ekologi Bronfenbrenner ${ }^{38}$ yang memandang bahwa perkembangan manusia dipengaruhi oleh konteks lingkungan, hubungan timbal balik antara individu dengan lingkungan yang akan membentuk tingkah laku individu tersebut. Teori ekologi Bronfenbrenner menjelaskan bahwa terdapat lima sistem lingkungan yang penting dalam kehidupan seseorang, yaitu: mikrosistem, mesosistem, meksosistem, makrosistem, dan kronosistem. Sistem lingkungan mikrosistem, yaitu setting lingkungan dimana individu tersebut hidup. Pada mikrosistem inilah interaksi yang paling langsung dengan agen-agen sosial berlangsung. Lapas maupun lapasustik sebenarnya merupakan sistem yang lebih luas dalam kehidupan seseorang, namun dalam konteks residivis narkoba pengguna ini, hal tersebut menjadi agen-agen sosial yang langsung berinteraksi dengan subjek. Lapas maupun lapasustik menjadi lingkungan yang memiliki peran penting secara berbeda dalam kehidupan subjek untuk menjadi residivis narkoba pengguna. Hal tersebut ditunjukkan dalam tabel 2 di bawah ini.

Tabel 2. Perbandingan Lapas dan Lapasustik

\begin{tabular}{|l|l|l|}
\hline Keterangan & Lapasustik & Lapas \\
\hline Jenis Kasus WBP & Narkoba & $\begin{array}{l}\text { Narkoba \& kasus } \\
\text { kriminal lain }\end{array}$ \\
\hline Perlakuan Petugas & $\begin{array}{l}\text { Sama, lebih } \\
\text { humanis }\end{array}$ & $\begin{array}{l}\text { Berbeda antara kasus } \\
\text { narkoba \& kriminal } \\
\text { lain }\end{array}$ \\
\hline Pembinaan & $\begin{array}{l}\text { Ada: pembinaan } \\
\text { kepribadian \& }\end{array}$ & $\begin{array}{l}\text { Ada: pembinaan } \\
\text { kepribadian \& }\end{array}$ \\
\hline
\end{tabular}

38 Bronfenbrenner, Urie. The Ecology of Human Development. (USA: Harvard University Press, 1979). 


\begin{tabular}{|l|l|l|}
\hline & $\begin{array}{l}\text { pembinaan } \\
\text { kemandirian, } \\
\text { namun masih } \\
\text { menekankan } \\
\text { pembinaan } \\
\text { keagamaan }\end{array}$ & $\begin{array}{l}\text { pembinaan } \\
\text { kemandirian, namun } \\
\text { masih menekankan } \\
\text { pembinaan } \\
\text { keagamaan }\end{array}$ \\
\hline $\begin{array}{l}\text { Rehabilitasi medis } \\
\text { \& sosial }\end{array}$ & $\begin{array}{l}\text { Ada: lebih baik, } \\
\text { lebih terencana \& } \\
\text { terorganisir, namun } \\
\text { belum menyentuh } \\
\text { kebutuhan } \\
\text { personal, } \\
\text { dipersepsikan WBP } \\
\text { belum efektif }\end{array}$ & $\begin{array}{l}\text { Ada: sebatas } \\
\text { terlaksana, } \\
\text { dipersepsikan WBP } \\
\text { belum efektif }\end{array}$ \\
\hline $\begin{array}{l}\text { Tidak } \\
\text { memunculkan self } \\
\text { contempt, } \\
\text { memunculkan bias } \\
\text { kognitif: } \\
\text { kenyamanan } \\
\text { sebagai napi } \\
\text { narkoba }\end{array}$ & $\begin{array}{l}\text { Tidak memunculkan } \\
\text { self contempt, } \\
\text { memunculkan } \\
\text { stratifikasi sosial dan } \\
\text { bias kognitif: status } \\
\text { napi narkoba berbeda }\end{array}$ \\
\hline
\end{tabular}

\section{Penutup}

UU No. 12 Tahun 1995 tentang Pemasyarakatan dan UU. No. 35 Tahun 2009 tentang Narkotika belum terimplementasi sepenuhnya pada lapas maupun lapasustik. Dibuktikan dari perlakuan petugas lapas yang berbeda antara kasus narkoba dan kasus kriminal lain, sementara perlakuan petugas lapasustik sama dan lebih humanis, sehingga berdampak pada residivisme. Pada keduanya terdapat pembinaan kepribadian maupun kemandirian, namun masih menekankan pembinaan keagamaan. Rehabilitasi medis dan sosial dipersepsikan belum efektif. Kedua lapas tidak memunculkan self contempt, namun memunculkan bias kognitif. Lapas maupun lapasustik menjadi lingkungan yang berperan penting secara berbeda untuk menjadi residivis narkoba pengguna, namun lapasustik merupakan lingkungan yang lebih kondusif 
dalam mencapai tujuan pemasyarakatan bagi residivis narkoba pengguna.

\section{Daftar Putsaka}

Bandura, A. The Self System in Reciprocal Determinism. American Psychologist. 44(9), 1978.

Arief, Barda Nawawi. Bunga Rampai Kebijakan Hukum Pidana, Perkembangan Penyusunan Konsep KUHP Baru, Jakarta: Kencana, 2010. Sebagaimana dikuti dari: Rifanly Potabuga, "Pidana Penjara Menurut KUHP", Lex Crimen Vol.I, No.4. Okt-Des, 2012.

Baro, A.L. "Effect of Cognitive Restructuring Program on Inmate Institutional Behavior". Criminal Justice \& Behavior. American Association for Correctional Psychology, 26(4). Desember, 1999.

Beck, A. T., \& Weishaar, M. E. Cognitive Therapy. In A. Freeman, K. M. Simon, L. E. Beutler, \& H. Arkowitz (Eds.), Comprehensive Handbook of Cognitive Therapy. Plenum Press, 1989.

Bronfenbrenner, Urie. The Ecology of Human Development. USA: Harvard University Press, 1979.

Cochran, J.C. "Breaches in the Wall: Imprisonment, Social Support, and Recidivism". Journal of Research in Crime and Delinquency. 51(2), 2014.

Costigan, G, Crofts N, \& Reid G. Pedoman mengurangi dampak buruk narkoba di Asia. Edisi Indonesia. Yogyakarta: Warta AIDS, 2001.

Evans, E., Huang, D., Hser, Y.I. “High Risk Offenderes Partisipating in Court-Supervised Substance Abuse Treatment: Characteristic, Treatment Received, \& Factors Associated with Recidivism". Journal of Behavioral Health Service $\mathcal{E}$ Research, 38(4), Oktober, 2011. 
Fazel S dan Wolf A, "A Systematic Review of Criminal Recidivism Rates Worldwide: Current Difficulties and Recommendations for Best Practice", PLoS ONE 10(6): e0130390. doi:10.1371/journal.pone.0130390, June 18, 2015.

Henslin, James M. Sosiologi dengan Pendekatan Membumi. Jakarta: Erlangga, 2006.

Iskandar, A. Jalan Lurus: Penanganan Penyalahguna Narkotika dalam Konstruksi Hukum Positif. Karawang: CV. Viva Tanpas, 2015. Jumarni. "Peran Lembaga Pemasyarakatan Kelas II A Watampone Dalam Pembinaan Narapidana Penyalahgunaan Narkoba Berdasarkan Undang-Undang Nomor 12 Tahun 1995 tentang Pemasyarakatan". Jurnal Al-Dustur. Volume 2 No 2, Desember, 2019.

Kamus Besar Bahasa Indonesia, (Edisi ketiga), Jakarta: Balai Pustaka, 2002.

Kitab Undang-Undang Hukum Pidana

Kartikawati, Reni. "Stratifikasi Sosial Warga Binaan Wanita di Rutan Pondok Bambu". Jurnal Sosiologi Masyarakat, Vol.17, No. 2, Juli, 2012.

Laporan Kegiatan Pengkajian Hak Manusia di Wilayah Karakteristik Narapidana Kasus Narkotika oleh Bidang Hak Asasi Manusia Divisi Pelayanan Hukum dan HAM Kantor Wilayah Kementrian Hukum dan HAM DKI Jakarta tahun 2019

Listwan, S.J., Sundt, J.L., \& Holsinger, A.M. "The Effect on Drug Court Programming on Recidivism: The Cincinati Experience. Crime \& Delinquency, 49(3), Juli, 2003.doi: $10.1177 / 0011128703253762$.

Maspidah. "Peran Lembaga Pemasyarakatan Narkotika Klas IIA Sungguminasa dalam Pembinaan Narapidana". (Tesis-Program Pasca Sarjana Universitas Negeri Makasar, 2019). Max Weber. Sosiologi.Yogyakarta: Pustaka Pelajar, 2006.

McKiernan,P., Shamblen,SR., Collins,DA., Strader,TN., \& Kokoski, C. "Creating Lasting Family Connections: Reducing 
Recidivism with Community-Based Family Strengthening Model". Criminal Justice Policy Review. 24(1), 2013.

Miles, M.B \& Huberman, A. Qualitative Data Analysis, A Sourcebook of New Method. California: Sage Publication, 1994.

Morse, J. M. Designing Funded Qualitative Research. In N. K. Denzin \& Y. S. Lincoln (Eds.), Handbook of Qualitative Research California: Sage Publications, Inc, 1994.

Priyatno, Dwija. Sistem Pelaksanaan Pidana Penjara di Indonesia. Bandung: PT. Refika Aditama, 2006.

Putra, RA. "Peranan Lembaga Kemasyarakatan dalam Pembinaan

Narapidana Penyalahgunaan Narkotika (Studi di Lembaga

Pemasyarakatan Klas IIA Sragen)". (Tesis--Fakultas

Hukum Universitas Muhamadiyah, Surakarta, 2013).

Riyan. "Peran Lembaga Pemasyarakatan Dalam Membina Narapidana Penyalahgunaan Narkotika Menurut Uu Nomor 12 Tahun 1995 Ditinjau Dari Fiqh Siyasah (Studi Pada Lembaga Pemasyarakatan Kelas 1 Bandar Lampung)" (Skripsi - Universitas Islam Negeri Raden Intan, Lampung, 2019)

Robert, A. Baron \& Nyla, R. Branscombe. Social Psychology. USA: Pearson Education, Inc, 2012.

Sakidjo, Aruan dan Poernomo, Bambang. Hukum Pidana Dasar

Aturan Umum Hukum Pidana Kodifikasi. Jakarta: Ghalia Indonesia, 1990.

Sasangka, Hari. Narkotika dan Psikotropika dalam Hukum Pidana. Bandung: Mandar Maju, 2003.

Schneiders, A.A. Personal Adjustment and Mental Health. New York: Holt, Reinhart and Winston Inc, 1999.

Soekanto, Soerjono. Sosiologi Suatu Pengantar. Jakarta: Rajawali Pers, 2009.

Suparman, Fana. Napi Narkoba Bikin Lapas dan Rutan di Indonesia Kelebihan Kapasitas, Berita Satu (27 Desember 2018), dalam https://www.beritasatu.com/nasional/529886-napinarkoba-bikin-lapas-dan-rutan-di-indonesia-kelebihankapasitas 
UU No. 12 Tahun 1995 tentang Pemasyarakatan

UU No 5 Tahun 1997 tentang Psikotropika

UU. No. 35 Tahun 2009 tentang Narkotika

Wilson, D.B., Bouffard, L.A., \& Mackenzie, D.L. "A Quantitative Review of Structured, Group-Oriented, CognitiveBehavioral Programs for Offenders". Criminal Justice And Behavior. American Association for Correctional Psychology, 32(2), April, 2005. doi: 10.1177/0093854804272889

Woessner, G \& Schwedler, A. “Correctional Treatment of Sexual and Violent Offenders: Therapeutic Change, Prison Climate, and Recidivism". Criminal Justice and Behavior. Published online, 13 February, 2014. doi: 10.1177/0093854813

Yusuf, U \& Raissa, P. “Pengaruh Terapi Kognitif Perilaku terhadap Peningkatan Kontrol Diri pada Residivis". Jurnal Intervensi Psikologi). 3(2). 2011.Diakses dari database portal Garuda 